\title{
Phonological priming reflects lexical competition
}

\author{
MARYBETH HAMBURGER and LOUISA M. SLOWIACZEK \\ State University of New York, Albany, New York
}

\begin{abstract}
A phonological relationship between a prime and a target produces facilitation when one or two initial phonemes are shared (low-similarity facilitation) but produces interference when more phonemes are shared (high-similarity interference; Slowiaczek \& Hamburger, 1992). Although low-similarity facilitation appears to be a strategic effect (Goldinger, Luce, Pisoni, \& Marcario, 1992), this result cannot generalize to high-similarity interference because the two effects are dissociated (Slowiaczek \& Hamburger, 1992). In the present study, strategic processing in high-similarity interference was investigated. The phonological relatedness proportion (PRP) and the prime-target interstimulus interval (ISI) were varied in a shadowing experiment. Low-similarity facilitation was found only with a high PRP and long ISI, but high-similarity interference was found regardless of PRP and ISI. These results suggest that strategies influence low-similarity facilitation, but high-similarity interference reflects automatic processing.
\end{abstract}

Several studies (e.g., Goldinger, Luce, Pisoni, \& Marcario, 1992; Jakimik, Cole, \& Rudnicky, 1985; Radeau, Morais, \& Dewier, 1989; Slowiaczek \& Hamburger, 1992) have examined the role of phonology in auditory word recognition by using a priming paradigm (Meyer \& Schvandeveldt, 1971) in which a target word is preceded by a prime that shares some of its initial phonemes. Two dissociable effects have been obtained in this area of research: low-similarity facilitation and high-similarity interference (Slowiaczek \& Hamburger, 1992). Although low-similarity facilitation involves strategic processes (Goldinger et al., 1992), the influence of strategies in highsimilarity interference has not been investigated.

Determining the role of strategic processes in phonological priming is critical for models of spoken word recognition that propose operations relying on the phonology and predict phonological priming under various circumstances. For instance, in cohort theory (Marslen-Wilson, 1987), word recognition begins by activating a cohort of possible lexical candidates whose initial phonemes match the incoming signal. As such, a phonologically related prime could preactivate a target and facilitate responses. Another theory, the neighborhood activation model (NAM; Luce, 1986), suggests that similar-sounding lexical entries compete during word recognition. That is, the probability of recognizing a word is a function of the number, word frequency, and phonetic similarity of the word's neighbors. Presenting a phonologically related prime effectively increases its frequency and, thus, increases the competition between it and the target. A connectionist model pro-

The research reported here was supported by the National Institutes of Health Grant NS-29286 to the University at Albany, State University of New York. The authors thank Emily Soltano, John Munson, Kelly Romano, Kenya Strong, and Marc Frank for assistance in completing this project, and Jim Neely for comments on the manuscript. Correspondence should be addressed to the second author at the Department of Psychology, State University of New York, Albany, NY 12222 (email: 1s707@cnsvax.albany.edu). posed by Slowiaczek and Hamburger (1992) allows a phonological relationship between a prime and a target to cause facilitation when one or two initial phonemes are common to both words (low similarity) and to cause competition when several initial phonemes are shared by both words (high similarity). In this model, phonemes are represented at a prelexical level and words are represented at a lexical level; excitatory connections link consistent units at different levels, and inhibitory connections link units within a level. The model predicts facilitation when phoneme units excite lexical units and interference when highly similar lexical units compete.

Low-similarity facilitation refers to faster and more accurate responses to an auditory target (e.g., STOP) when it is preceded by a prime that begins with the same one or two phonemes (e.g., SLAB or STAB). This effect has been found in an identification-in-noise task (Goldinger et al., 1992; Slowiaczek, Nusbaum, \& Pisoni, 1987), a lexicaldecision-in-noise task (Goldinger et al., 1992), and a shadowing task (Slowiaczek \& Hamburger, 1992). However, this facilitation effect is subject to strategic influences. Using a lexical-decision-in-noise task, Goldinger et al. (1992) varied the percentage of related trials (the relatedness proportion) and the prime-target interstimulus interval (ISI) while testing low-similarity phonological priming. They found that low-similarity facilitation occurs only if a high $(50 \%)$ phonological relatedness proportion, or PRP, is used. Indeed, with a low (10\%) PRP and a short $(50 \mathrm{msec})$ ISI, low-similarity phonological priming produced inhibition. Within the semantic priming literature, Neely (1991) and Neely and Keefe (1989) have argued that strategic effects are maximized with a high relatedness proportion and a long ISI and are minimized by the reverse. Because low-similarity phonological facilitation occurred only under conditions that promote strategic processing, Goldinger et al. (1992) argued that it is due to a strategy in which listeners "assume the initial phoneme of the target is the same as the initial phoneme of the prime" (p. 1217). 
High-similarity interference, on the other hand, refers to increasing response times as the amount of phonological overlap between primes and targets increases. It has been observed when primes and targets share three initial phonemes (e.g., STOCK-STOP) or their first syllables (e.g., PARURE-PALAIS) in the lexical decision (Radeau et al., 1989; Slowiaczek \& Pisoni, 1986) or the shadowing (Radeau et al., 1989; Slowiaczek \& Hamburger, 1992) tasks. Because Slowiaczek and Hamburger (1992) found that reaction times (RTs) in the high-similarity condition were always slower than RTs in the low-similarity condition but not always slower than in the unrelated condition, this effect has been termed interference rather than inhibition. ${ }^{1}$ Although strategic processing mediates low-similarity facilitation, no work to date has tested whether such processing influences high-similarity interference (see Table 1).

To generalize from low-similarity phonological priming and conclude that high-similarity phonological priming is a strategic effect is not appropriate, because the two effects are dissociated. In a study using the shadowing task, the amount of phonological overlap between primes and targets $(0,1,2$, or 3 initial phonemes), prime modality (auditory or visual) and prime lexicality (word or nonword) were varied (Slowiaczek \& Hamburger, 1992). Low-similarity facilitation was found when word or nonword primes shared their initial phoneme with targets, but only when primes were auditorily presented. Because low-similarity facilitation was dependent on prime modality but not prime lexicality, Slowiaczek and Hamburger (1992) argued that low-similarity facilitation occurs prelexically and is due to excitation spreading from phoneme units to lexical units. Research indicating that lowsimilarity facilitation is strategic (Goldinger et al., 1992) suggests that this prelexical excitation is not a basic part of the word recognition system. High-similarity interference, however, was found for auditory and visual primes, but only when primes were words. On the basis of these data, Slowiaczek and Hamburger (1992) argued that this effect is the result of lexical competition due to strong inhibitory links connecting units representing phonologically similar words.

Because low-similarity facilitation and high-similarity interference are dissociated, evidence concerning one type of phonological priming cannot be generalized to the other. The previous work addressing strategic processing in phonological priming (Goldinger et al., 1992) has only tested low-similarity effects. Thus, it does not apply to high-similarity interference. The work that has examined high-similarity interference (Radeau et al., 1989; Slowiaczek \& Hamburger, 1992; Slowiaczek \& Pisoni, 1986) has not addressed strategic processing.

Given the fact that previous work has typically found facilitation for low-similarity prime-target pairs and interference for high-similarity prime-target pairs, Goldinger et al.'s (1992) finding of inhibition from low-similarity phonological priming under conditions that minimized strategic processing is surprising. Although this nonstrategic low-similarity inhibition could perhaps be related to high-similarity interference, there are reasons to believe otherwise. First, as previously stated, high-similarity and low-similarity phonological priming effects are dissociable, and Goldinger et al. (1992) tested only the lowsimilarity condition. Second, Goldinger et al. suggested that the inhibitory phonological priming that they found may be due to phonetic rather than phonological similarity between the primes and targets. Finally, this lowsimilarity inhibition was obtained only with degraded targets (i.e., targets were presented in a background of noise). Thus, Goldinger et al.'s results are not directly related to high-similarity interference and cannot determine whether or not high-similarity phonological priming is strategic.

The fact that low-similarity facilitation appears to be a strategic effect is problematic for models such as cohort theory, which predict only facilitatory effects due to phonological priming. If high-similarity interference is

Table 1

Phonological Priming Effects Observed in Auditory Word Recognition

\begin{tabular}{|c|c|c|c|c|c|c|}
\hline $\begin{array}{c}\text { Phonological } \\
\text { Overlap }\end{array}$ & Task & $\begin{array}{c}\text { Prime } \\
\text { Modality }\end{array}$ & $\begin{array}{c}\text { Prime } \\
\text { Lexicality }\end{array}$ & $\operatorname{PRP}(\%)$ & $\begin{array}{c}\text { ISI } \\
\text { (in msec) }\end{array}$ & Citation \\
\hline \multicolumn{7}{|c|}{ Facilitation Effect } \\
\hline 1 or 2 phonemes & ID in noise & Auditory & $\begin{array}{l}\text { Word or } \\
\text { nonword }\end{array}$ & 80 & 500 & Slowiaczek et al. (1987) \\
\hline 1 phoneme & Shadowing & Auditory & $\begin{array}{l}\text { Word or } \\
\text { nonword }\end{array}$ & 75 or 80 & 500 & Slowiaczek \& Hamburger (1992) \\
\hline l phoneme & $\begin{array}{l}\text { ID or LDT } \\
\text { in noise }\end{array}$ & Auditory & Word & 50 & 50 or 500 & Goldinger et al. (1992) \\
\hline \multicolumn{7}{|c|}{ Interference Effect } \\
\hline 3 phonemes & LDT & Auditory & Word & 100 & 500 & Slowiaczek \& Pisoni (1986) \\
\hline 1 syllable & $\begin{array}{l}\text { Shadowing } \\
\text { or LDT }\end{array}$ & Auditory & Word & 71 & $700^{*}$ & Radeau et al. (1989) \\
\hline 3 phonemes & Shadowing & $\begin{array}{l}\text { Auditory or } \\
\text { visual }\end{array}$ & Word & 75 or 80 & 500 & Slowiaczek \& Hamburger (1992) \\
\hline 1 phoneme & LDT in noise & Auditory & Word & 10 & 50 & Goldinger et al. (1992) \\
\hline
\end{tabular}

Note-PRP, phonological relatedness proportion; ISI, interstimulus interval; ID, identification; LDT, lexical decision task. *Radeau et al. (1989) reported a 700 -msec stimulus onset asynchrony, but they did not report the duration of the prime words. Thus, the ISI for this experiment is uncertain. 
found to be strategically induced, it would indicate that the lexical competition is also not an integral part of the word recognition system. Such a finding would challenge not only Slowiaczek and Hamburger's model but also other models of form priming that posit lexical competition (Lupker \& Colombo, 1994).

The present study was designed to examine the influence of strategies in high-similarity interference. Auditory target words were primed by auditory words that shared no phonemes with their targets (the unrelated condition), one or two phonemes with their targets (the low-similarity conditions), or three phonemes with their targets (the highsimilarity condition). The high-expectancy condition used a high (75\%) PRP and long (500 msec) ISI to replicate the results found by Slowiaczek and Hamburger (1992) and provide a baseline to which the other condition can be compared. The low-expectancy condition was designed to minimize strategic effects by using a low (21\%) PRP and a short ( $50 \mathrm{msec}$ ) ISI. PRP and ISI were intentionally confounded to provide the strongest test of participants' expectancies. Because low-similarity facilitation is subject to strategic influences (Goldinger et al., 1992), it should be greater in the high-expectancy condition than in the low-expectancy condition. If, unlike lowsimilarity facilitation, high-similarity interference is not strategic, it should occur in both high- and low-expectancy conditions. However, if high-similarity interference is strategic, it should be greater in the high-expectancy condition than in the low-expectancy condition.

\section{METHOD}

\section{Participants}

A total of 132 participants were tested. Of these, 114 participants were recruited from the psychology participant pool at the University at $\mathrm{Al}$ bany, State University of New York, and received partial credit toward a course research requirement in exchange for their participation. Another 18 participants were recruited through advertisements posted on the campus of the University at Albany and were paid $\$ 5$ to participate in this experiment and two unrelated experiments in one 45-min session. All participants were native English speakers with no known hearing or speech disorders. Forty-eight participants were tested in the highexpectancy condition and 84 in the low-expectancy condition. ${ }^{2}$

\footnotetext{
Materials

One hundred monosyllabic English words three to five phonemes in length were selected as targets for the high-expectancy condition; 98 of these served as targets in the low-expectancy condition. Mean target frequency was 129 occurrences per million (Kučera \& Francis, 1967). Mean target duration was $636 \mathrm{msec}$. Four monosyllabic word primes three to six phonemes long were paired with each target. Primes and targets were related such that they shared no phonemes (the unrelated condition), the initial phoneme only (Condition 1), the first two phonemes (Condition 2), or the first three phonemes (Condition 3). All primes in Condition 3 were at least four phonemes long. ${ }^{3}$

A female talker digitally recorded the stimuli using a Zenith 386 DX20 personal computer and an Electro Voice PL88L microphone. The stimuli were digitized at a sampling rate of $10 \mathrm{kHz}$ using a 12-bit analogto-digital converter (Data Translation DT 2821) and low-pass filtered at $4.8 \mathrm{kHz}$ with a TTE $411 \mathrm{AFS}$ amplifier/filter. The words were edited from the lists using a digital waveform editor and stored as single files on a computer disk for playback during the experiment.

For the high-expectancy condition, 4 stimulus lists of 100 prime-target pairs were constructed so that, within a list, 25 targets were primed in each condition $(\mathrm{PRP}=75 \%)$. For the low-expectancy condition, 14 lists
}

of 98 prime-target pairs were constructed such that, within a list, 77 targets were primed in the unrelated condition and 7 targets were primed in each of Conditions 1,2 , and 3 (PRP $=21 \%$ ). Within lists, no stimulus was used more than once. Across lists, all targets were primed in all conditions. Each participant was tested on one list.

The presentation of stimuli, experimental timing, and recording of RTs were controlled by a Zenith 386 DX20 personal computer. Stimuli were presented over a pair of Sennheiser HD430 earphones at $80 \mathrm{~dB}$ SPL using a digital-to-analog converter (Data Translation DT2821) and the TTE 411AFS amplifier/filter. RTs were collected using an Electro Voice PL88L microphone attached to a voice key interfaced to the computer

\section{Procedure}

The participants were tested individually. Instructions informed the participants that on each trial they would hear two stimulus items over their earphones and that they should say aloud only the second item as quickly and accurately as possible. The participants completed 10 practice trials. In the high-expectancy condition, they completed $100 \mathrm{ex}-$ perimental trials; in the low-expectancy condition, they completed 98 experimental trials. The order of the experimental trials was randomized for each participant. The experimenter wrote down the participants' responses so that accuracy could be determined later.

A typical trial proceeded as follows. A warning phrase, GET READY, appeared in the center of the monitor's screen for $1 \mathrm{sec}$ at the beginning of each trial. It was followed by a dark, blank screen during which the prime was presented over earphones. In the high-expectancy condition, a 500-msec ISI followed prime presentation; in the low-expectancy condition, the ISI was $50 \mathrm{msec}$. Then, the target was presented over the earphones. The computer recorded the time from the target onset until the participant responded by saying the target aloud. If a noise other than the participant's response triggered the voice key, the trial was marked as "no response" and that RT was excluded from the analysis. The next trial began $1 \mathrm{sec}$ after the participant's response or $3.5 \mathrm{sec}$ after the target if the participant failed to respond.

\section{RESULTS}

Because of extremely high (greater than $20 \%$ ) error rates, six items were excluded from all analyses. One other item was excluded from the analysis of the highexpectancy condition. Response accuracy and response latency data from the remaining items were analyzed separately. The percentage of correctly shadowed words in each priming condition was determined for each participant. Mean RTs and error rates in each condition are reported in Table 2 . Because error rates were consistently low, they were not analyzed further.

Examination of Table 2 shows that the results of the high-expectancy condition replicate Slowiaczek and Hamburger (1992). RTs in Conditions 1 and 2 were faster than RTs in the unrelated condition (low-similarity facilitation). RTs were slower in Condition 3 than RTs in Conditions 1 and 2 (high-similarity interference). In the low-expectancy condition, on the other hand, high-similarity interference is apparent, but low-similarity facilitation is not.

To test the statistical significance of these differences, RT data were subjected to 2 (expectancy) $\times 4$ (priming condition) analyses of variance (ANOVAs) conducted by participants $(F 1)$ and items $(F 2)$. In the participant analysis, expectancy was treated as a between-participants variable and priming condition was treated as a withinparticipants variable. In the item analysis, both factors were treated as within-items variables. The degrees of freedom were modified using the Huynh-Feldt correction to adjust for violations of the sphericity assumption com- 
Table 2

Mean Reaction Times (RT, in Milliseconds) and Error Rates as a Function of Expectancy and the Number of Shared Phonemes Between the Prime and the Target

\begin{tabular}{|c|c|c|c|c|c|c|c|c|}
\hline \multirow[b]{3}{*}{ Expectancy } & \multicolumn{8}{|c|}{ Priming Condition } \\
\hline & \multicolumn{2}{|c|}{ Unrelated } & \multicolumn{2}{|r|}{1} & \multicolumn{2}{|r|}{2} & \multicolumn{2}{|r|}{3} \\
\hline & RT & Error Rate & RT & Error Rate & RT & Error Rate & RT & Error Rate \\
\hline Hig & 1,032 & .06 & 1,019 & .05 & 1,007 & .06 & 1,032 & .04 \\
\hline Low & 923 & .06 & 919 & .07 & 915 & .06 & 959 & .05 \\
\hline
\end{tabular}

mon in repeated measures designs (Jaccard \& Ackerman, 1985; Maxwell \& Avery, 1982). Results with $p<.05$ were considered significant and will be reported. All results reported are significant except for specifically denoted null results. These analyses revealed that responses were slower in the high-expectancy condition $(1,023 \mathrm{msec})$ than in the low-expectancy condition $(929 \mathrm{msec})[F 1(1,130)$ $=26.55, M S_{\mathrm{e}}=40,223 ; F 2(1,91)=668.23, M S_{\mathrm{e}}=$ $2,397]$. This effect was likely due to the shorter ISI (50 msec) in the low-expectancy condition that sped up the overall pace of the experiment. As a result, the participants were more engaged by the task and more likely to respond quickly. Stone, Joaquim, and Gabrieli (1995) report a similar effect of the timing of experimental trials on RTs. The main effect of priming condition was also significant $\left[F 1(3,358)=3.66, M S_{\mathrm{e}}=2,028 ; F 2(3,262)=\right.$ $\left.3.18, M S_{\mathrm{e}}=2,994\right]$. Most importantly, the interaction between expectancy and priming condition was significant $\left[F 1(3,358)=3.66, M S_{\mathrm{e}}=2,028 ; \quad F 2(3,268)=3.18\right.$, $\left.M S_{\mathrm{e}}=2,994\right]$. This result suggests that the PRP and ISI manipulations in the present study were strong enough to influence expectancy and that this expectancy is involved in phonological priming.

To further investigate the interaction, each expectancy condition was analyzed separately using one-way ANOVAs with four levels of prime type. These analyses indicated that the effect of priming condition was significant in both the high-expectancy condition $\left[F 1(3,127)=3.67, M S_{\mathrm{e}}=\right.$ 1,$\left.866 ; F 2(3,238)=3.57, M S_{\mathrm{e}}=3,272\right]$ and the lowexpectancy condition $\left[F 1(3,223)=16.20, M S_{\mathrm{e}}=2,119\right.$; $\left.F 2(3,264)=9.07, M S_{\mathrm{e}}=3,778\right]$. Within each expectancy condition, follow-up analyses were conducted to further examine the effect of priming condition and determine if these results replicate Slowiaczek and Hamburger (1992). These comparisons were conducted by participants $(t 1)$ and by items $(t 2)$ using a correlated groups $t$ test with a modified Bonferroni correction (Holland \& Copenhaver, 1988; Jaccard, Becker, \& Wood, 1984). In the high-expectancy condition, RTs in Condition 2 $(1,007 \mathrm{msec})$ were faster than RTs in the unrelated condition $(1,032 \mathrm{msec})[t 1(47)=2.70, S E=45.78 ; t 2(92)=$ $2.40, S E=67.81]$ and Condition $3(1,032 \mathrm{msec})[t 1(47)$ $=3.26, S E=37.04 ; t 2(92)=2.86, S E=50.14]$. In the low-expectancy condition, RTs in Condition $3(959 \mathrm{msec})$ were slower than RTs in the unrelated condition (923 $\mathrm{msec})$ $[t 1(83)=6.06, S E=38.09 ; t 2(91)=3.72, S E=59.25]$, Condition $1(919 \mathrm{msec})[t 1(83)=4.83, S E=53.48$; $t 2(91)=3.75, S E=64.51]$, and Condition $2(915 \mathrm{msec})$ $[t 1(83)=5.53, S E=51.63 ; t 2(91)=4.40, S E=67.63]$. No other differences were significant in any analyses.

The two main findings of Slowiaczek and Hamburger (1992) were replicated in the high-expectancy condition. First, a decrease in RTs was obtained as the number of phonemes shared between the prime and the target increased from zero to two. Slowiaczek and Hamburger (1992) reported that this low-similarity facilitation was significant when only the first phoneme was shared between the prime and the target. However, in none of their studies did the difference between Condition 1 and Condition 2 approach significance. Similarly, the difference between Condition 1 and Condition 2 in the present study was not significant $[t 1(47)=1.38, S E=43.66$, n.s.; $t 2(92)=$ $0.97, S E=56.14$, n.s.]. Also, in both studies, significant low-similarity facilitation was observed between the unrelated condition and the average of Conditions 1 and 2 . In the high-expectancy condition, the unrelated condition $(1,032 \mathrm{msec})$ was slower than the average of Conditions 1 and $2(1,014 \mathrm{msec})[t 1(47)=2.08, S E=38.19 ; t 2(92)=$ 2.61, $S E=47.06]$. Likewise, in Slowiaczek and Hamburger's (1992) Experiment 2A, the unrelated condition (953 $\mathrm{msec})$ was slower than the average of Conditions 1 and $2(938 \mathrm{msec})[t 1(39)=2.05, S E=30.35 ; t 2(99)=$ $2.26, S E=35.63]$. Thus, the low-similarity facilitation observed between the unrelated condition and Condition 2 here and that observed between the unrelated condition and Condition 1 in Slowiaczek and Hamburger (1992) are functionally equivalent. Second, high-similarity interference was obtained between Condition 2 and Condition 3. Slowiaczek and Hamburger (1992) found a similar increase in RTs between Condition 1 (934 msec) and Condition 3 (969 msec). Averaging RTs in Conditions 1 and 2 , as with the analysis of low-similarity facilitation, and comparing that average to RTs in Condition 3 revealed a significant difference in the high-expectancy condition $[t 1(47)=2.34, S E=38.67 ; t 2(92)=2.75, S E=$ 43.21] and in Slowiaczek and Hamburger's (1992) Experiment $2 \mathrm{~A}[t 1(39)=4.53, S E=31.76 ; t 2(99)=5.59$, $S E=38.83]$. Thus, both the low-similarity facilitation and the high-similarity interference effects found in Slowiaczek and Hamburger (1992) were replicated in the high-expectancy condition.

The results of the low-expectancy condition indicate that, in the absence of the participants' expectancies, only high-similarity interference, and not low-similarity facilitation, results from phonological priming. In the lowexpectancy condition, low-similarity facilitation was not 
found; RTs did not decrease between the unrelated condition and Condition 1 or 2. The lack of low-similarity facilitation under low-expectancy conditions replicates Goldinger et al. (1992). However, high-similarity interference was obtained in the low-expectancy condition; RTs were slower in Condition 3 than in the other conditions. This result suggests that high-similarity interference in phonological priming experiments was not a product of the participants' expectancies but rather reflects automatic competition among highly similar lexical items.

The amount of low-similarity facilitation (unrelated condition minus Condition 2) was reduced from $25 \mathrm{msec}$ in the high-expectancy condition to $8 \mathrm{msec}$ in the lowexpectancy condition, suggesting that the low-similarity facilitation effect is due to strategic processing. This conclusion is supported by the fact that significant amounts of low-similarity facilitation were observed in the highexpectancy condition but not in the low-expectancy condition. To determine if the expected interaction was significant, 2 (unrelated or Condition 2 ) $\times 2$ (expectancy condition) ANOVAs were conducted. These analyses revealed a significant effect of prime type $[F 1(1,130)=$ $\left.7.19, M S_{\mathrm{e}}=1,784 ; F 2(1,91)=6.67, M S_{\mathrm{e}}=3,754\right]$ and a significant effect of expectancy $[F 1(1,130)=35.29$, $\left.M S_{\mathrm{e}}=19,463 ; F 2(1,91)=603.73, M S_{\mathrm{e}}=1,760\right]$. However, the interaction did not reach significance $[F 1(1,130)$ $\left.=1.30, M S_{\mathrm{e}}=1,784 ; F 2(1,91)=.88, M S_{\mathrm{e}}=2,642\right]$. One interpretation of this result is that strategic processing was reduced in the low-expectancy condition, but it was not completely eliminated. The fact that Goldinger et al. (1992) found low-similarity inhibition may indicate that if the PRP had been reduced further from $21 \%$ to $10 \%$, strategic processing (and with it the low-similarity facilitation) may have been further eliminated and the interaction may have been significant.

Of greater interest in the present study, high-similarity interference was observed under both high- and lowexpectancy conditions, indicating that this effect is not strategic. The amount of high-similarity interference was larger in the low-expectancy condition $(44 \mathrm{msec})$ than in the high-expectancy condition $(25 \mathrm{msec})$, indicating that competition between highly similar items is not enhanced by expectancy. To test this interaction, 2 (Condition 2 or 3) $\times 2$ (expectancy condition) ANOVAs were conducted. These analyses revealed significant effects of prime type $\left[F 1(1,130)=32.64, M S_{\mathrm{e}}=2,121 ; F 2(1,91)=21.66\right.$, $\left.M S_{\mathrm{e}}=4,465\right]$ and expectancy condition $[F 1(1,130)=$ $\left.26.62, M S_{\mathrm{e}}=18,212 ; F 2(1,91)=221.52, M S_{\mathrm{e}}=3,436\right]$, and a significant interaction $\left[F 1(1,130)=3.40, M S_{\mathrm{e}}=\right.$ 2,$\left.121 ; F 2(1,91)=5.56, M S_{\mathrm{e}}=2,178\right]$. The same pattern of results is observed when comparing Condition 3 with the average of Conditions 1 and 2, with significant effects of prime type $\left[F 1(1,130)=30.50, M S_{\mathrm{e}}=1,862\right.$; $\left.F 2(1,91)=22.32, M S_{\mathrm{e}}=3,419\right]$ and expectancy condition $\left[F 1(1,130)=26.69, M S_{\mathrm{e}}=18,681 ; F 2(1,91)=\right.$ $\left.294.80, M S_{\mathrm{e}}=2,572\right]$, and a significant interaction $\left[F 1(1,130)=4.76, M S_{\mathrm{e}}=1,862 ; F 2(1,91)=7.01\right.$, $\left.M S_{\mathrm{e}}=1,673\right]$. The interaction reflects the finding that the high-similarity interference increased when strategic processing was reduced. The high-similarity interference may have increased in the low-expectancy condition because it was not being counteracted by the strategic facilitation that causes low-similarity facilitation. The fact that high-similarity priming switched from merely interference in the high-expectancy condition to an inhibition effect in the low-expectancy condition may have been due to the elimination of the strategic facilitation.

\section{DISCUSSION}

The goal of the present study was to examine the influence of strategies on two dissociated phonological priming effects. The findings of the present experiment support the view that high-similarity interference reflects basic auditory word recognition processes. However, lowsimilarity facilitation in phonological priming appears to be strategic. These conclusions are supported by the data showing that high-similarity interference was maintained under all conditions, whereas low-similarity facilitation occurred only under the high-expectancy condition.

Low-similarity facilitation appears to be strategically mediated in that it is enhanced by participants' expectancies. The fact that Goldinger et al. (1992) obtained low-similarity inhibition and we did not may be due to their use of a lower PRP ( $10 \%$ vs. $21 \%$ ), the lexical decision task rather than the shadowing task, and degraded targets rather than targets presented in the clear. A lower PRP should result in less strategic facilitation, whereas the lexical decision task and target degradation generally enhance priming effects (Neely, 1991).

Although the nature of low-similarity facilitation in phonological priming experiments is debatable, this paper has demonstrated that the dissociated high-similarity interference does occur under conditions in which strategic processing is reduced. Thus, this phonological priming effect most likely reflects the operations of the auditory word recognition system. The manipulation of expectancy had no effect on the presence of high-similarity interference. In fact, greater high-similarity interference was observed under low-expectancy conditions. The results of Slowiaczek and Hamburger (1992) indicate that high-similarity interference is a lexical effect possibly due to competition between lexical representations of phonologically similar words. Thus, the present study in conjunction with the phonological priming literature supports this view and advocates models of word recognition that include some mechanism to account for intralexical form-based competition (Lupker \& Colombo, 1994; Slowiaczek \& Hamburger, 1992).

\section{REFERENCES}

Goldinger, S. D., Luce, P. A., Pisoni, D. B., \& Marcario, J. K. (1992). Form-based priming in spoken word recognition: The roles of competition and bias. Journal of Experimental Psychology: Learning, Memory, \& Cognition, 18, 1211-1238.

Holland, B. S., \& COPEnhaVer, M. D. (1988). Improved Bonferronitype multiple testing procedures. Psychological Bulletin, 104, 145-149.

JACCARD, J., \& ACKERMAN, L. (1985). Repeated measures analysis of means in clinical research. Journal of Consulting \& Clinical Psychology, 53, 426-428.

JACCARD, J., BeCKer, M. A., \& WoOD, G. (1984). Pairwise multiple comparison procedures: A review. Psychological Bulletin, 96, 589596.

JAKIMIK, J., COLE, R. A., \& RudNiCKy, A. (1985). Sound and spelling in spoken word recognition. Journal of Memory \& Language, 24, 165-178.

KuČERA, H., \& FranCIS, W. N. (1967). Computational analysis of presentday American English. Providence, RI: Brown University Press.

LUCE, P. A. (1986). Neighborhoods of words in the mental lexicon. Unpublished doctoral dissertation, Indiana University, Bloomington.

LUPKER, S. J., \& COLOMBo, L. (1994). Inhibitory effects in form priming: Evaluating a phonological competition explanation. Journal of Experimental Psychology: Human Perception \& Performance, 20, 437-451. 
MARSLEN-Wilson, W. D. (1987). Functional parallelism in spoken word recognition. Cognition, 25, 71-102.

MaXWell, S., \& AVerY, R. (1982). Small sample profile analysis with many variables. Psychological Bulletin, 92, 778-785.

Meyer, D. E., \& Schvaneveldt, R. W. (1971). Facilitation in recognizing pairs of words: Evidence of a dependence between retrieval operations. Journal of Experimental Psychology, 90, 227-234.

NEELY, J. H. (1991). Semantic priming effects in visual word recognition: A selective review of current findings and theories. In D. Besner \& G. Humphreys (Eds.), Basic processes in reading: Visual word recognition (pp. 264-336). Hillsdale, NJ: Erlbaum.

NeELY, J. H., \& KeEFE, D. E. (1989). Semantic effects on visual word processing: A hybrid prospective/retrospective processing theory. In G. H. Bower (Ed.), The psychology of learning and motivation: Advances in research and theory (Vol. 24, pp. 207-248). New York: Academic Press.

Radeau, M., Morais, J., \& Dewier, A. (1989). Phonological priming in spoken word recognition: Task effects. Memory \& Cognition, 17, 525-535.

Slowiaczek, L. M., \& Hamburger, M. B. (1992). Prelexical facilitation and lexical interference in auditory word recognition. Journal of Experimental Psychology: Learning, Memory, \& Cognition, 18, 1239-1250.

Slowiaczek, L. M., Nusbaum, H. C., \& Pisoni, D. B. (1987). Phonological priming in auditory word recognition. Journal of Experimental Psychology: Learning, Memory, \& Cognition, 13, 64-75.
SlowiaczeK, L. M., \& Pisoni, D. B. (1986). Effects of phonological similarity on priming in auditory lexical decision. Memory \& Cognition, 14, 230-237.

Stone, M., Joaquim, S. G., \& Gabrieli, J. D. E. (1995, November). Anchoring effects in speed of word processing. Paper presented at the 36th Annual Meeting of the Psychonomic Society, Los Angeles

\section{NOTES}

1. Slowiaczek and Hamburger (1992) used the term interference when Condition 3 differed from Condition 1 or Condition 2 but not from the unrelated condition. Under all conditions, Slowiaczek and Hamburger (1992) found interference, but it resulted in inhibition relative to the unrelated condition only when no low-similarity facilitation was apparent. In the present paper, we have used the term high-similarity interference to describe both of these effects, because we believe that the interference and the inhibition reflect the same mechanism.

2. More participants were tested in the low-expectancy condition because of the small number of observations per participant per priming condition when a low PRP is used.

3. Contact the authors for a complete list of stimuli.

(Manuscript received June 2, 1995; revision accepted for publication June $19,1996$. 